\title{
Prognostic Role of MicroRNA Let-7 in Non-Small Cell Lung Cancer: A Systematic Review and Meta- Analysis
}

\section{Xiaoting Zhang}

Shenzhen Bao'an Distrcit Songgang People's Hospital

Huaning Kang

Guangzhou Medical University

Guihong Chen ( $\nabla$ guihongchen1972@163.com )

Shenzhen Bao'an District Songgang People's Hospital

Xiaofeng Li ( $\square$ tah-520@163.com)

Peking University Shenzhen Hospital https://orcid.org/0000-0002-3946-5791

Research article

Keywords: MicroRNA let-7, Non-small cell lung cancer, Prognosis, Overall survival, Meta-analysis

Posted Date: July 28th, 2020

DOI: https://doi.org/10.21203/rs.3.rs-46072/v1

License: (c) (i) This work is licensed under a Creative Commons Attribution 4.0 International License.

Read Full License 


\section{Prognostic Role of MicroRNA Let-7 in Non-Small Cell Lung Cancer: A \\ Systematic Review and Meta-Analysis}

Xiaoting Zhang ${ }^{+1}$, Huaning Kang ${ }^{+2}$, Guihong Chen ${ }^{* 1}$, Xiaofeng Li ${ }^{* 3}$

1 Shenzhen Bao'an District Songgang People's Hospital, Shenzhen, 518100, China

2 School of Pharmaceutical Sciences, Guangzhou Medical University, Guangzhou, 511436, China

3 Department of Laboratory Medicine, Peking University Shenzhen Hospital, Shenzhen,

Guangdong, P.R. China

$\dagger$ contributed equally to this work

*Correspondence: Xiaofeng Li e-mail: 13530597138@163.com and Guihong Chen email: guihongchen1972@163.com 


\section{Abstract}

Background Recent studies have shown that MicroRNAs can be used as potential biomarkers to the prognosis in non-small cell lung cancer (NSCLC). Hence, we conducted this meta-analysis to evaluate the prognostic role of microRNA let-7 in NSCLC patients.

Methods PubMed, Web of Science, Medline and the Cochrane Library were searched for relevant studies. Eligible studies were met specific inclusion and exclusion criteria. Stata 15.1 was used to calculate the pooled parameters.

Results A total of 11 studies involving 2278 NSCLC patients were included in this meta-analysis. Subgroup analyses established that the heterogeneity was connected with ethnicity and follow-up time. The results suggested that the low expression of microRNA let-7 indicates a poor overall survival rate, with a hazard ratio value of 0.99 (95\% CI: 0.64-1.34, $\mathrm{P}<0.05)$.

Conclusions Low expression of microRNA let-7 is closely related to the poor prognosis of NSCLC, so microRNA let-7 may become a new biomarker to evaluate the prognosis of NSCLC patients.

Keywords MicroRNA let-7; Non-small cell lung cancer; Prognosis; Overall survival; Meta-analysis 


\section{Background}

Lung cancer is one of the most common malignant tumors in the world. It is also the leading cause of mortality in men and women[1]. Non-small cell lung cancer (NSCLC) accounts for the majority of lung cancer. Despite a better understanding of the pathogenesis of NSCLC and the development of effective therapies including surgical treatment, radiotherapy, chemotherapy and targeted therapy, the overall 5-year survival is extremely low $(\sim 15 \%) \quad[2,3]$. Even when treatment is initiated early in the disease, patients showed high recurrence rates, underscoring the need for a deeper understanding of the biology of NSCLC and the identification of more effective biomarkers.

MicroRNAs, approximately 20-25 nucleotides in length, are short and non-coding RNA molecules that negatively regulate gene expression at the post-transcriptional level [4]. MicroRNAs are encoded by specific genes and play an important role in inhibiting mRNA translation or promoting mRNA degradation [5, 6]. MicroRNAs take effects in many biological processes, such as inflammation, cell growth, apoptosis, development, differentiation, endocrine homeostasis, and even cancer $[7,8]$. MicroRNA let-7 is a class of microRNAs. Studies have shown that microRNA let-7 family was less expressed in tumor tissues than normal counterparts [9], indicating that microRNA let-7 family members are crucial in the development of cancer.

To elucidate the role of microRNA let-7 as a prognostic biomarker, we performed a meta-analysis. This meta-analysis analyzed relevant studies to provide credible results on whether microRNA let-7 is a reliable prognostic biomarker for NSCLC patients. 


\section{Methods}

\section{Search strategy}

Two researchers performed a literature search from the online databases PubMed, Web of Science, Medline and the Cochrane Library to assess the role of microRNA let7 in the prognosis of NSCLC. We selected English literature on human subject published before February 16, 2020. The keywords included "let-7," "microRNA," "miRNA," "non-small cell lung cancer" in combination with "NSCLC". We also manually searched the reference lists of the eligible literature to find more potential relevant studies.

\section{Criteria for inclusion and exclusion}

All included studies had to meet the following criteria: (1) research subjects were NSCLC patients; (2) studies should investigate the association between microRNA let7 expression level and overall survival of the patients; (3) relevant data information should be provided. If one or more of the following criteria were met, the literature was excluded: (1) animal experiments or fundamental investigation; (2) the study did not emphasis on NSCLC; (3) no survival outcomes or reported results could not be calculated; (4) duplicate publications or articles in the form of reviews, case reports, editorials, letters, and annals.

\section{Quality assessment and data extraction}

To ensure the quality of the meta-analysis, two researchers independently 
evaluated the quality of the selected studies using the guideline of the NewcastleOttawa Quality Assessment Scale (NOS) [10]. Each study had a score on a scale of 0 to 9 , and the study with a score higher than 6 was considered as high quality.

According to the selection criteria and quality assessment, relevant data were extracted from each study, including the name of the first author, year of publication, country of study, number of the research objects, type of microRNA let-7 family, sample source, detecting method, follow-up time, survival analysis data, cutoff point, hazard ratio (HR) values, and 95\% confidence intervals (CI). For the literature that only provided Kaplan-Meier curves, we extracted data from the survival graphs and the HR was estimated using the related statistical methods [11]. Two researchers independently extracted the data with cross-check and mutual agreement, and controversial studies were settled by a third researcher.

\section{Statistical analysis}

Stata 15.1 (StataSE 15, USA) was used to perform statistical analysis. The effects of $\mathrm{HR}$ and $95 \% \mathrm{CI}$ on microRNA let-7 expression level and NSCLC prognosis were evaluated. For unknown HR and 95\% CI, data were calculated from the survival curves using Engauge Digitizer 10.8. Heterogeneity among the studies were assessed by Cochran's Q test (P-values $\leq 0.05$ was considered statistically significant) and Higgins's $\mathrm{I}^{2}$ statistics (the values of 25,50 , and $75 \%$ represented low, medium, and high heterogeneity, respectively). When there was statistically significant heterogeneity (P $<0.05, \mathrm{I}^{2}>50 \%$ ), the random effect model was used, otherwise the fixed effect model 
was applied. Publication bias was described by the funnel plots with the Begg and Egger's regression test. $\mathrm{P}<0.05$ was considered statistically significant. Meanwhile, sensitivity analysis was performed to validate the stability of the results.

\section{Results}

\section{Characteristics of the included studies}

The results of literature retrieval were shown in Fig. 1. A total of 476 studies on microRNA let-7 and NSCLC prognosis were identified by screening PubMed, Web of Science, Medline, Cochrane Library and other sources. Ten duplicates were excluded. A further 425 were removed after screening the titles and abstracts. The remaining 51 were evaluated in full-text reading. And 40 were excluded for the reasons that 9 were non-human studies; 14 lacked critical survival data; and 17 were irrelevant to specific researches. Therefore, 11 studies were included in the meta-analysis [12-22].

The main characteristics of the included studies, which were arranged by ascending order of the year of publication, were listed in Table 1. A total of 2278 NSCLC patients were included in the meta-analysis. Among the 11 studies from included articles, 6 were performed on Asian populations and 5 were on Caucasian populations. All studies detected the microRNA let-7 expression in tissues by quantitative real-time polymerase chain reaction (qRT-PCR) assay. The cutoff points of the expressions were different. All studies analyzed the correlation between microRNA let-7 and overall survival, among which only 9 researches directly showed HR values and $95 \% \mathrm{CI}$, while we calculated HR values and 95\% CI of the other 2 articles. In 
addition, the quality assessment of included studies were shown in Table 1 and the medium NOS score was 7 , indicating that all eligible studies were of high quality.

\section{Outcomes from eligible studies}

The meta-analysis was conducted to investigate the prognostic role of microRNA let-7 in NSCLC patients. Data analysis using Stata 15.1 statistical software showed statistical heterogeneity between the studies $\left(\mathrm{P}=0.000, \mathrm{I}^{2}=91.4 \%\right)$. Therefore, we used the random effect model to calculate the parameters included in the studies. The low microRNA let-7 expression was associated with poor overall survival $(\mathrm{HR}=0.99,95 \%$ CI: 0.64-1.34, $\mathrm{P}<0.05$, Fig. 2).

\section{Subgroup analysis}

A significant heterogeneity was observed in the meta-analysis, and subgroup analyses were conducted to explore the source of heterogeneity. We performed subgroup analyses based on ethnicity and follow-up time. The results of each subgroup analysis were shown in Fig. 3 and 4.

\section{Publication bias and sensitivity analysis}

Begg and Egger's regression were conducted to assess the likelihood of publication bias in this meta-analysis. Begg's regression test showed $\operatorname{Pr}>|z|=0.876>0.05$, Egger's regression test showed $\mathrm{P}>|\mathrm{t}|=0.657>0.05$ (Fig. 5 and 6). The results were not statistically significant, suggesting that the probability of publication bias was low. 
Sensitivity analysis refers to analyzing the impact of each study on the stability of metaanalysis results by omitting any single study in sequence. Sensitivity analysis showed that the pooled results were stable in this meta-analysis (Fig. 7).

\section{Discussion}

MicroRNAs bind to specific target mRNAs by base pairing and negatively regulate gene expression or inhibit translation by degrading target mRNA. This regulation of gene expression plays a critical role in development, cell differentiation and apoptosis [23]. The association between abnormal microRNAs expression and the prognosis of lung cancer, especially NSCLC, has been evaluated in a number of meta-analysis studies. MicroRNA let-7 is a member of the microRNA family and serves as a sequential control factor in determining cell fate [12]. This study summarized the latest researches on microRNA let-7 in NSCLC, focusing on the role of microRNA let-7 as a biomarker in the prognosis of NSCLC patients.

According to Xia et al. [16], the low expression of microRNA let-7 is closely related to the prognosis of NSCLC. More samples of publications have been included in our work. We demonstrated that the low microRNA let-7 expression is statistically associated with overall survival. The HR of low microRNA let-7 expression in NSCLC was 0.99 , indicating that low let-7 expression is associated with poor prognosis of NSCLC. As we can see from Fig. 2, the significant heterogeneity was found in the study. We therefore performed subgroup analyses of selected articles based on ethnicity and follow-up time. They proposed different subtotal HR values and found heterogeneity in 
subgroups. This may explain the source of heterogeneity in the meta-analysis.

This meta-analysis was designed to investigate the role of microRNA let-7 in the prognosis of NSCLC patients, making it a reliable biomarker and providing clinicians with valuable information for the most effective treatment of NSCLC patients and adjusting treatment strategies. Although a systematic and comprehensive meta-analysis has been conducted, there were still limitations remaining. Firstly, the number of patients included in the study was insufficient to obtain more accurate results, and the basic clinical features of the patients were also different, which could mainly explain the heterogeneity. Secondly, due to the lack of accurate HR values in the original papers, we calculated the HR values in the two studies. Studies that cannot calculate HR values have been removed from the analysis, which may be less persuasive. Finally, there was inevitably a publication bias between studies because positive results are more likely to be published, which may affect the results. However, despite there are heterogeneity, biases, and other limitations that make our study somewhat incomplete, the potential of microRNA let-7 as prognostic biomarker cannot be underestimated. More large-scale and standard studies, as well as a better understanding of microRNA let-7's mechanism of action and target, will enable further understanding of the role of microRNA let-7 in NSCLC prognosis and clinical application.

\section{Conclusions}

In summary, this meta-analysis demonstrates the role of microRNA let-7 in predicting prognosis in NSCLC patients. Low expression of microRNA let-7 is closely related to 
the poor prognosis of NSCLC, so microRNA let-7 may become a new biomarker to evaluate the prognosis of NSCLC patients.

\section{Abbreviations}

NSCLC: non-small cell lung cancer; CIs: Confidence intervals; HRs: Hazard ratios;

\section{Acknowledgements}

We would like to thank the researchers and study participants for their contributions.

\section{Author contribution}

XTZ and HLK collected and analyzed the data, wrote the paper; HLK performed quality assessment and analyzed the data. XFL and GHC conceived and designed this study. All authors reviewed the paper. All authors read and approved the final manuscript.

\section{Conflict of interest}

The authors have no conflicts of interest to disclose.

\section{Funding}

The study was supported in part by National Natural Science Foundation of China (81801517 to L.X.F.), Medjaden Academy \& Research Foundation for Young Scientists (Grant No. MJR20190009) to L.X.F and the fund of "San-ming" Project of Medicine in Shenzhen (NO.SZSM201812088).

\section{Availability of data and materials}

All data are included in this article. The datasets used and/or analysed during the current study available from the corresponding author on reasonable request. 


\section{Ethics approval and consent to participate}

Not applicable.

\section{Consent for publication}

Not applicable.

\section{References}

1. Siegel RL, Miller KD, Jemal A: Cancer statistics, 2020. CA Cancer J Clin 2020, 70(1):7-30.

2. Saintigny P, Burger JA: Recent advances in non-small cell lung cancer biology and clinical management. Discovery Medicine 2012, 13(71):287-297.

3. a DWPM, b NGM: New driver mutations in non-small-cell lung cancer. 2011.

4. Pichinuk E, Broday L, Wreschner DH: Endogenous RNA cleavages at the ribosomal SRL site likely reflect miRNA (miR) mediated translational suppression. Biochem Biophys Res Commun 2011, 414(4):0-711.

5. Paranjape T, Slack FJ, Weidhaas JB: MicroRNAs: tools for cancer diagnostics. Gut 2009, 58(11):1546-1554.

6. Mukherji S, Ebert MS, Zheng GX, Tsang JS, Sharp PA, van Oudenaarden A: MicroRNAs can generate thresholds in target gene expression. Nat Genet 2011, 43(9):854-859.

7. Alvarez-Garcia I, Miska EA: MicroRNA functions in animal development and human disease. Development 2005, 132(21):4653-4662.

8. Zhou, Chang: MicroRNA-373 is upregulated and targets TNFAIP1 in human gastric cancer, contributing to tumorigenesis. Oncology letters 2013, 6(5):1427-1434.

9. Schultz J, Lorenz P, Gross G, Ibrahim S, Kunz M: MicroRNA let-7b targets important cell cycle molecules in malignant melanoma cells and interferes with anchorage-independent growth. Cell 
Res 2008, 18(5):549-557.

10. Stang A: Critical evaluation of the Newcastle-Ottawa scale for the assessment of the quality of nonrandomized studies in meta-analyses. Eur J Epidemiol 2010.

11. Tierney JF, Stewart LA, Ghersi D, Burdett S, Sydes MR: Practical methods for incorporating summary time-to-event data into meta-analysis. Trials 2007, 8:16.

12. Takamizawa J, Konishi H, Yanagisawa K, Tomida S, Osada H, Endoh H, Harano T, Yatabe Y, Nagino M, Nimura Y et al: Reduced expression of the let-7 microRNAs in human lung cancers in association with shortened postoperative survival. Cancer Res 2004, 64(11):3753-3756.

13. Yanaihara N, Caplen N, Bowman E, Seike M, Kumamoto K, Yi M, Stephens RM, Okamoto A, Yokota J, Tanaka T et al: Unique microRNA molecular profiles in lung cancer diagnosis and prognosis. Cancer cell 2006, 9(3):189-198.

14. Yu SL, Chen HY, Chang GC, Chen CY, Chen HW, Singh S, Cheng CL, Yu CJ, Lee YC, Chen HS et al: MicroRNA signature predicts survival and relapse in lung cancer. Cancer cell 2008, 13(1):48-57.

15. Landi MT, Zhao Y, Rotunno M, Koshiol J, Liu H, Bergen AW, Rubagotti M, Goldstein AM, Linnoila I, Marincola FM et al: MicroRNA expression differentiates histology and predicts survival of lung cancer. Clin Cancer Res 2010, 16(2):430-441.

16. Xia XM, Jin WY, Shi RZ, Zhang YF, Chen J: Clinical significance and the correlation of expression between Let-7 and K-ras in non-small cell lung cancer. Oncology letters 2010, 1(6):1045-1047.

17. Voortman J, Goto A, Mendiboure J, Sohn JJ, Schetter AJ, Saito M, Dunant A, Pham TC, Petrini I, Lee A et al: MicroRNA expression and clinical outcomes in patients treated with adjuvant 
chemotherapy after complete resection of non-small cell lung carcinoma. Cancer Res 2010, 70(21):8288-8298.

18. Zhang YK, Zhu WY, He JY, Chen DD, Huang YY, Le HB, Liu XG: miRNAs expression profiling to distinguish lung squamous-cell carcinoma from adenocarcinoma subtypes. $J$ Cancer Res Clin Oncol 2012, 138(10):1641-1650.

19. Edin J, Matija R, Dragan K, Peter KE, Eva S, Ermina I, Zorica R, Mitja KN, Giuseppe V: let7b and miR-126 Are Down-Regulated in Tumor Tissue and Correlate with Microvessel Density and Survival Outcomes in Non-Small-Cell Lung Cancer. PloS one 2012, 7(9):e45577-.

20. Capodanno A, Boldrini L, Proietti A, Alì G, Pelliccioni S, Niccoli C, D'Incecco A, Cappuzzo F, Chella A, Lucchi $\mathrm{M}$ et al: Let-7g and miR-21 expression in non-small cell lung cancer: correlation with clinicopathological and molecular features. Int J Oncol 2013, 43(3):765-774.

21. Zhao B, Han H, Chen J, Zhang Z, Li S, Fang F, Zheng Q, Ma Y, Zhang J, Wu N et al: MicroRNA let-7c inhibits migration and invasion of human non-small cell lung cancer by targeting ITGB3 and MAP4K3. Cancer Lett 2014, 342(1):43-51.

22. Shin KM, Jung DK, Hong MJ, Kang HJ, Lee WK, Yoo SS, Lee SY, Cha SI, Lee J, Kim CH et al: The pri-let-7a-2 $\mathrm{rs} 1143770 \mathrm{C}>\mathrm{T}$ is associated with prognosis of surgically resected non-small cell lung cancer. Gene 2016, 577(2):148-152.

23. Abrahante JE, Daul AL, Li M, Volk ML, Tennessen JM, Miller EA, Rougvie AE: The Caenorhabditis elegans hunchback-like gene lin-57/hbl-1 controls developmental time and is regulated by microRNAs. Dev Cell 2003, 4(5):625-637. 


\section{Figure legends:}

Figure 1.Methodological flow chart of the meta-analysis.

Figure 2. The forest plot of studies evaluating HRs of microRNA let-7 in the prognosis of NSCLC.

Figure 3. Meta-analysis of subtotal HRs based on different ethnicity in the prognosis of NSCLC patients.

Figure 4.Meta-analysis of subtotal HRs based on different follow-up time in the prognosis of NSCLC patients.

Figure 5. Begg's regression test for publication bias of this meta-analysis.

Figure 6. Egger's regression test for publication bias of this meta- analysis.

Figure 7. Sensitivity analysis to assess the stability of results. 
Table 1 Main characteristics of the studies included in the meta-analysis.

\begin{tabular}{|c|c|c|c|c|c|c|c|c|c|c|c|}
\hline Study ID & Country & $\begin{array}{l}\text { Sample } \\
\text { size }\end{array}$ & Let-7 & $\begin{array}{l}\text { Sample } \\
\text { source }\end{array}$ & $\begin{array}{l}\text { Analysis } \\
\text { platform }\end{array}$ & $\begin{array}{l}\text { Follow-up } \\
\text { time }\end{array}$ & Survival analysis & Cutoff point & $\begin{array}{l}\text { Hazard ratio } \\
(\mathrm{HR}) \text { value }\end{array}$ & $\begin{array}{l}\text { Quality } \\
\text { score }\end{array}$ & Ref \\
\hline $\begin{array}{l}\text { Takamizawa } \\
2004\end{array}$ & Japan & 143 & Let-7 & Tissue & qRT-PCR & $>5$ years & $\begin{array}{l}\text { Univariate Cox } \\
\text { analysis }\end{array}$ & $\begin{array}{l}\text { Hierar-chical } \\
\text { Clustering }\end{array}$ & Reported & 8 & 12 \\
\hline $\begin{array}{l}\text { Yanaihara } \\
2006\end{array}$ & USA & 52 & Let-7a-2 & Tissue & qRT-PCR & $>1$ years & $\begin{array}{l}\text { Kaplan-Meier } \\
\text { analysis }\end{array}$ & mean & Reported & 7 & 13 \\
\hline Yu 2008 & China & 112 & Let-7a & Tissue & qRT-PCR & 2 years & $\begin{array}{l}\text { Kaplan-Meier } \\
\text { analysis }\end{array}$ & median & Reported & 8 & 14 \\
\hline Landi 2010 & USA & 290 & Let-7e & Tissue & qRT-PCR & 5 years & $\begin{array}{l}\text { Kaplan-Meier } \\
\text { analysis }\end{array}$ & median & Reported & 8 & 15 \\
\hline Xia 2010 & China & 31 & Let-7 & Tissue & qRT-PCR & 3 years & $\begin{array}{l}\text { Kaplan-Meier } \\
\text { analysis }\end{array}$ & median & Calculated & 7 & 16 \\
\hline $\begin{array}{l}\text { Voortman } \\
2010\end{array}$ & USA & 639 & Let-7a & Tissue & qRT-PCR & 8 years & $\begin{array}{l}\text { Multivariate Cox } \\
\text { analysis }\end{array}$ & median & Reported & 7 & 17 \\
\hline Zhang 2012 & China & 51 & Let-7e & Tissue & qRT-PCR & $>2$ years & $\begin{array}{l}\text { Kaplan-Meier } \\
\text { analysis }\end{array}$ & median & Reported & 8 & 18 \\
\hline $\begin{array}{l}\text { Jusufovic } \\
2012\end{array}$ & $\begin{array}{l}\text { Bosnia and } \\
\text { Herzegovina }\end{array}$ & 50 & Let-7b & Tissue & qRT-PCR & 1 years & $\begin{array}{l}\text { Kaplan-Meier } \\
\text { analysis }\end{array}$ & median & Reported & 7 & 19 \\
\hline $\begin{array}{l}\text { Capodanno } \\
2013\end{array}$ & Italy & 55 & Let-7g & Tissue & qRT-PCR & 8 years & $\begin{array}{l}\text { Kaplan-Meier } \\
\text { analysis }\end{array}$ & median & Calculated & 7 & 20 \\
\hline Zhao 2014 & China & 94 & Let-7c & Tissue & qRT-PCR & 6 years & $\begin{array}{l}\text { Kaplan-Meier } \\
\text { analysis }\end{array}$ & median & Reported & 7 & 21 \\
\hline Shin 2016 & Korea & 761 & Let-7a-2 & Tissue & qRT-PCR & 5 years & $\begin{array}{l}\text { Kaplan-Meier } \\
\text { analysis }\end{array}$ & median & Reported & 6 & 22 \\
\hline
\end{tabular}


Figures

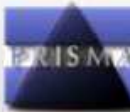

PRISMA 2009 Flow Diagram
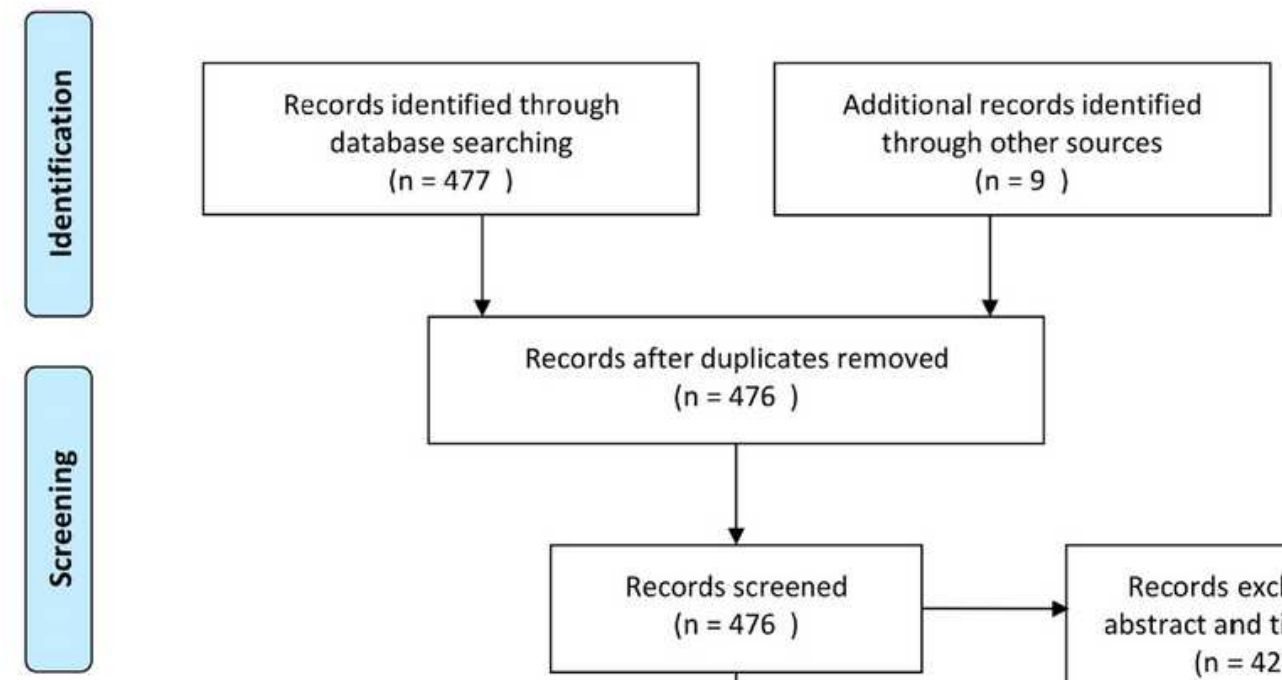

Records after duplicates removed

$$
(n=476 \text { ) }
$$
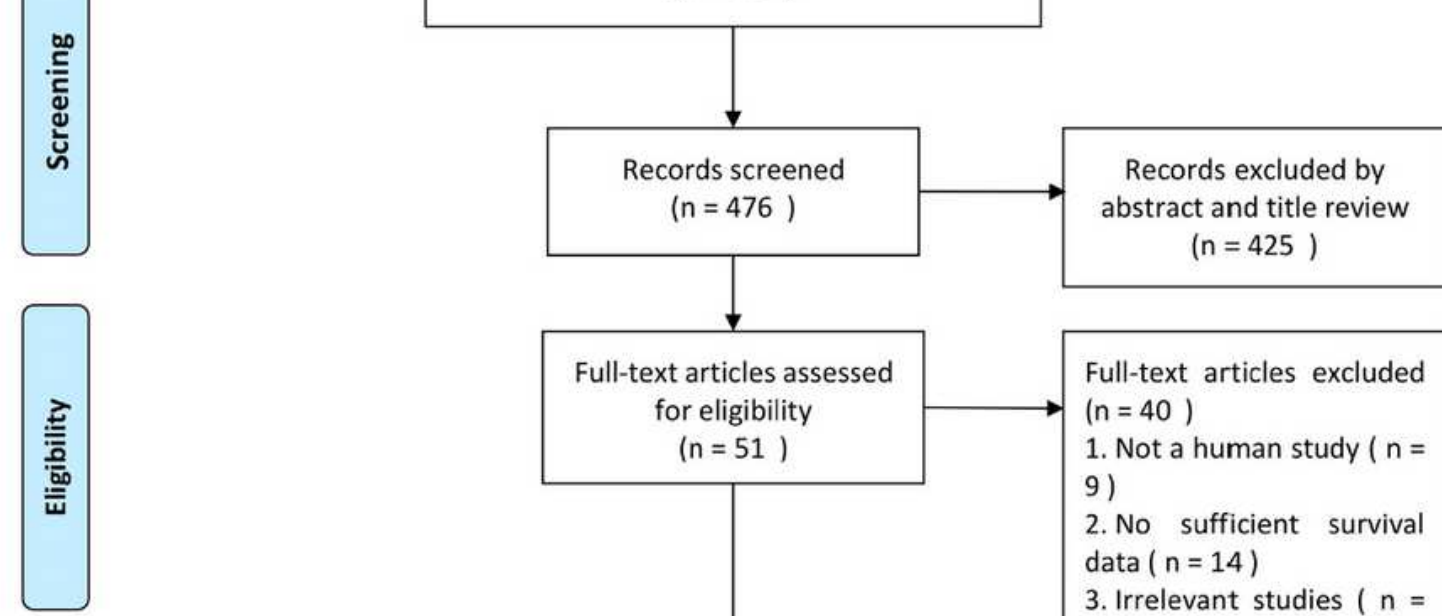

1. Not a human study $(n=$ 9)

2. No sufficient survival data $(n=14)$

3. Irrelevant studies $(n=$ 17)

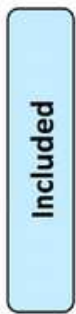

Studies included in

quantitative synthesis

(meta-analysis)

$(n=11)$

From: Moher D, Liberati A, Tetzlaff J, Altman DG, The PRISMA Group (2009). Preferred Reporting /tems for Systematic Reviews and MetaAnalyses: The PRISMA Statement. PLoS Med 6(6): e1000097, doi:10.1371/journal.pmed1000097

For more information, visit www.prisma-statement.org.

\section{Figure 1}

Methodological flow chart of the meta-analysis. 
Yanaihara 2006

Yu 2008

Landi 2010

Xia 2010

Voortman 2010

Zhang 2012

Jusufovic 2012

Capodanno 2013

Zhao 2014

Shin 2016

Overall (l-squared $=91.4 \%, p=0.000)$

NOTE: Weights are from random effects analysis

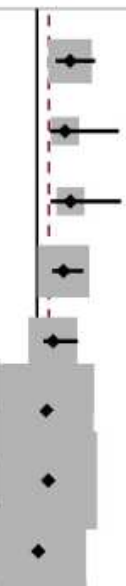

$2.78(1.56,4.89)$

$2.35(1.08,6.86)$

$2.81(1.13,7.01)$

$2.22(1.27,3.89)$

$1.35(0.53,3.43)$

$0.84(0.68,1.04)$

$1.04(1.01,1.07)$

$0.20(0.09,0.43)$

$>1.56(0.07,36.44)$

$1.57(0.85,2.88)$

$0.67(0.49,0.91)$

$0.99(0.64,1.34)$
3.61

1.36

1.32

5.25

4.50

18.94

19.91

19.04

0.04

7.44

18.60

100.00

\section{Figure 2}

The forest plot of studies evaluating HRs of microRNA let-7 in the prognosis of NSCLC. 
Study

ID
$\%$

$\mathrm{HR}(95 \% \mathrm{Cl})$

Weight

\begin{tabular}{|c|c|c|c|}
\hline \multirow{2}{*}{$\begin{array}{l}\text { Asian } \\
\text { Takamizawa } 2004\end{array}$} & \multicolumn{3}{|l|}{ i } \\
\hline & $\leftarrow$ & $2.78(1.56,4.89)$ & 3.61 \\
\hline Yu 2008 & - & $2.81(1.13,7.01)$ & 1.32 \\
\hline Xia 2010 & $\leftarrow$ & $1.35(0.53,3.43)$ & 4.50 \\
\hline Zhang 2012 & - & $1.04(1.01,1.07)$ & 19.91 \\
\hline Zhao 2014 & $\leftarrow$ & $1.57(0.85,2.88)$ & 7.44 \\
\hline Shin 2016 & • & $0.67(0.49,0.91)$ & 18.60 \\
\hline Subtotal $(I-$ squared $=73.1 \%, p=0.002)$ & l & $1.06(0.71,1.41)$ & 55.38 \\
\hline . & 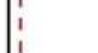 & & \\
\hline \multicolumn{4}{|l|}{ Caucasian } \\
\hline Yanaihara 2006 & 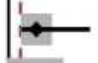 & $2.35(1.08,6.86)$ & 1.36 \\
\hline Landi 2010 & $\leftarrow$ & $2.22(1.27,3.89)$ & 5.25 \\
\hline Voortman 2010 & - & $0.84(0.68,1.04)$ & 18.94 \\
\hline Jusufovic 2012 & • & $0.20(0.09,0.43)$ & 19.04 \\
\hline Capodanno 2013 & $\infty^{\infty}$ & $1.56(0.07,36.44)$ & 0.04 \\
\hline Subtotal $(\mathrm{I}$-squared $=88.2 \%, \mathrm{p}=0.000)$ & 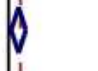 & $0.84(0.23,1.45)$ & 44.62 \\
\hline$\cdot$ & $\mid \begin{array}{l}1 \\
1\end{array}$ & & \\
\hline Overall $(I-$ squared $=91.4 \%, p=0.000)$ & 1 & $0.99(0.64,1.34)$ & 100.00 \\
\hline NOTE: Weights are from random effects analysis & : & & \\
\hline $\begin{aligned} & 1 \\
&-36.4\end{aligned}$ & 0 & & \\
\hline
\end{tabular}

\section{Figure 3}

Meta-analysis of subtotal HRs based on different ethnicity in the prognosis of NSCLC patients. 
Study

ID

$\geqq 5$ years

Takamizawa 2004

Landi 2010

Voortman 2010

Capodanno 2013

Zhao 2014

Shin 2016

Subtotal $($ I-squared $=63.8 \%, p=0.017)$

$<5$ years

Yanaihara 2006

Yu 2008

Xia 2010

Zhang 2012

Jusufovic 2012

Subtotal $($ I-squared $=95.7 \%, p=0.000)$

Overall $(\mathrm{I}$-squared $=91.4 \%, p=0.000)$

NOTE: Weights are from random effects analysis
$\operatorname{HR}(95 \% \mathrm{Cl})$

$\%$

Weight

$2.78(1.56,4.89) \quad 3.61$

$2.22(1.27,3.89) \quad 5.25$

$0.84(0.68,1.04) \quad 18.94$

$1.56(0.07,36.44) \quad 0.04$

$1.57(0.85,2.88) \quad 7.44$

$0.67(0.49,0.91) \quad 18.60$

$1.03(0.66,1.39) \quad 53.87$

$2.35(1.08,6.86) \quad 1.36$

$2.81(1.13,7.01) \quad 1.32$

$1.35(0.53,3.43) \quad 4.50$

$1.04(1.01,1.07) \quad 19.91$

$0.20(0.09,0.43) \quad 19.04$

$0.93(0.22,1.63) \quad 46.13$

$0.99(0.64,1.34) \quad 100.00$

\section{Figure 4}

Meta-analysis of subtotal HRs based on different follow-up time in the prognosis of NSCLC patients. 
Begg's funnel plot with pseudo $95 \%$ confidence limits

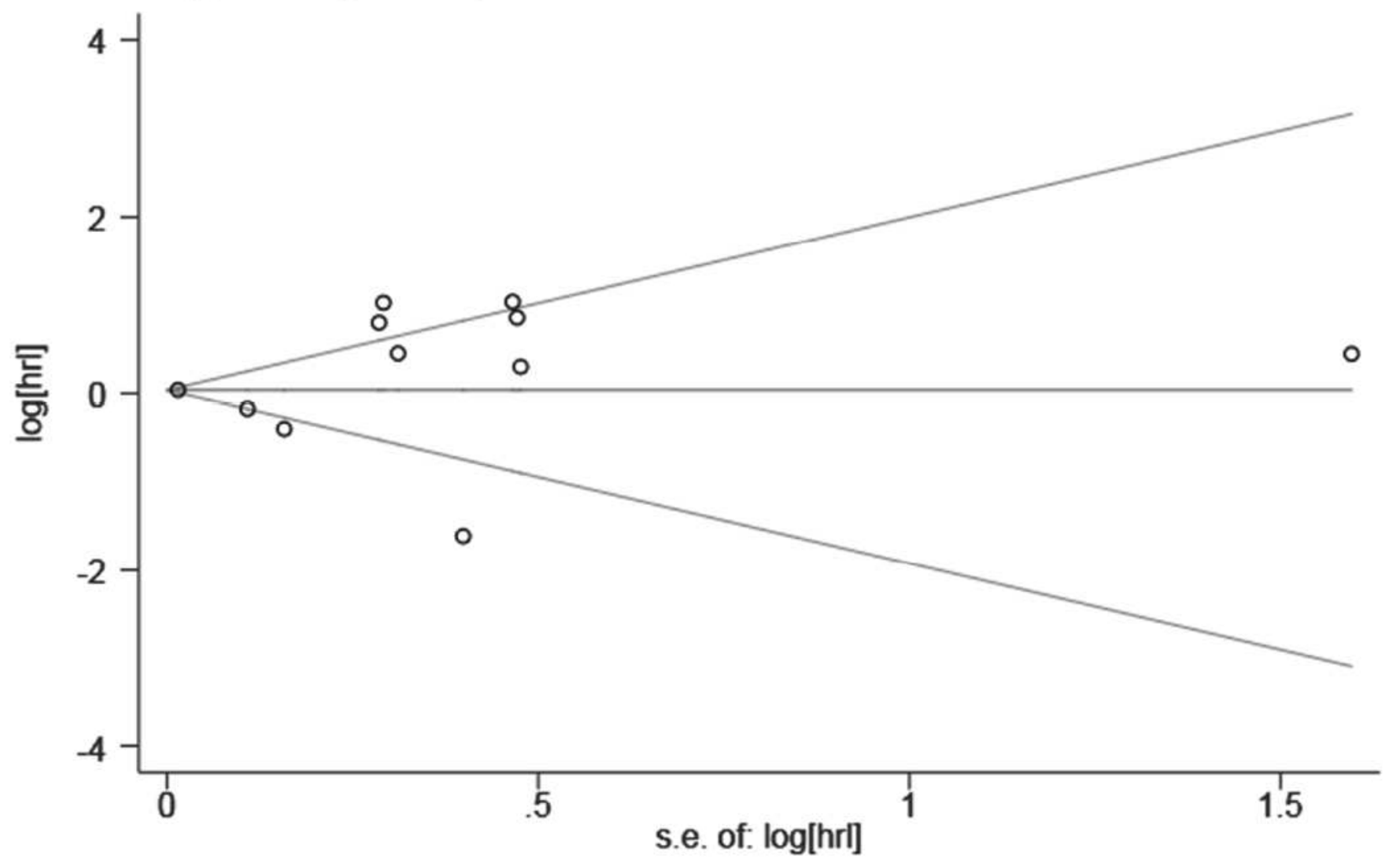

Figure 5

Begg's regression test for publication bias of this meta-analysis. 


\section{Egger's publication bias plot}

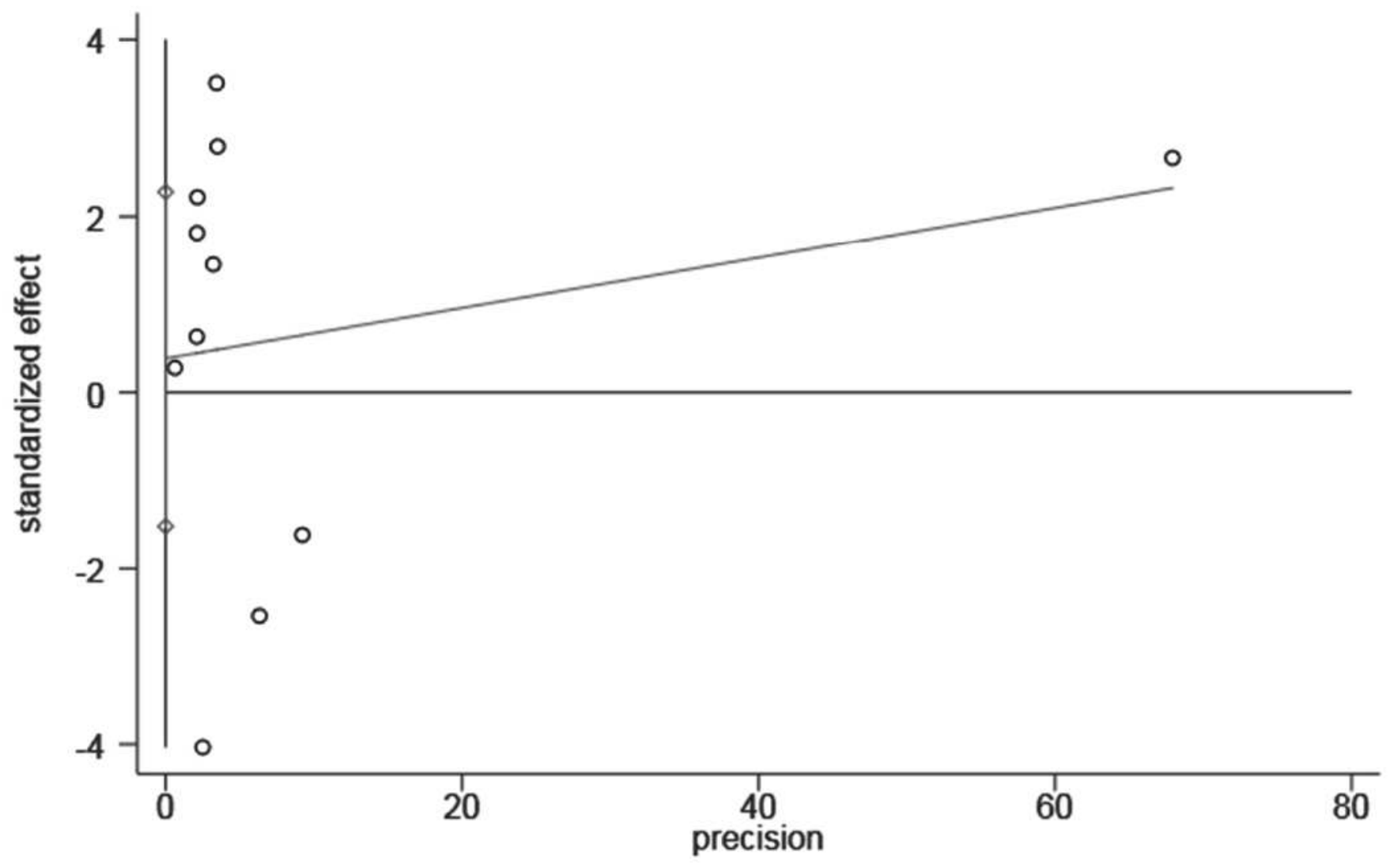

Figure 6

Egger's regression test for publication bias of this meta- analysis. 
Meta-analysis estimates, given named study is omitted

\section{Lower Cl Limit OEstimate I Upper Cl Limit}

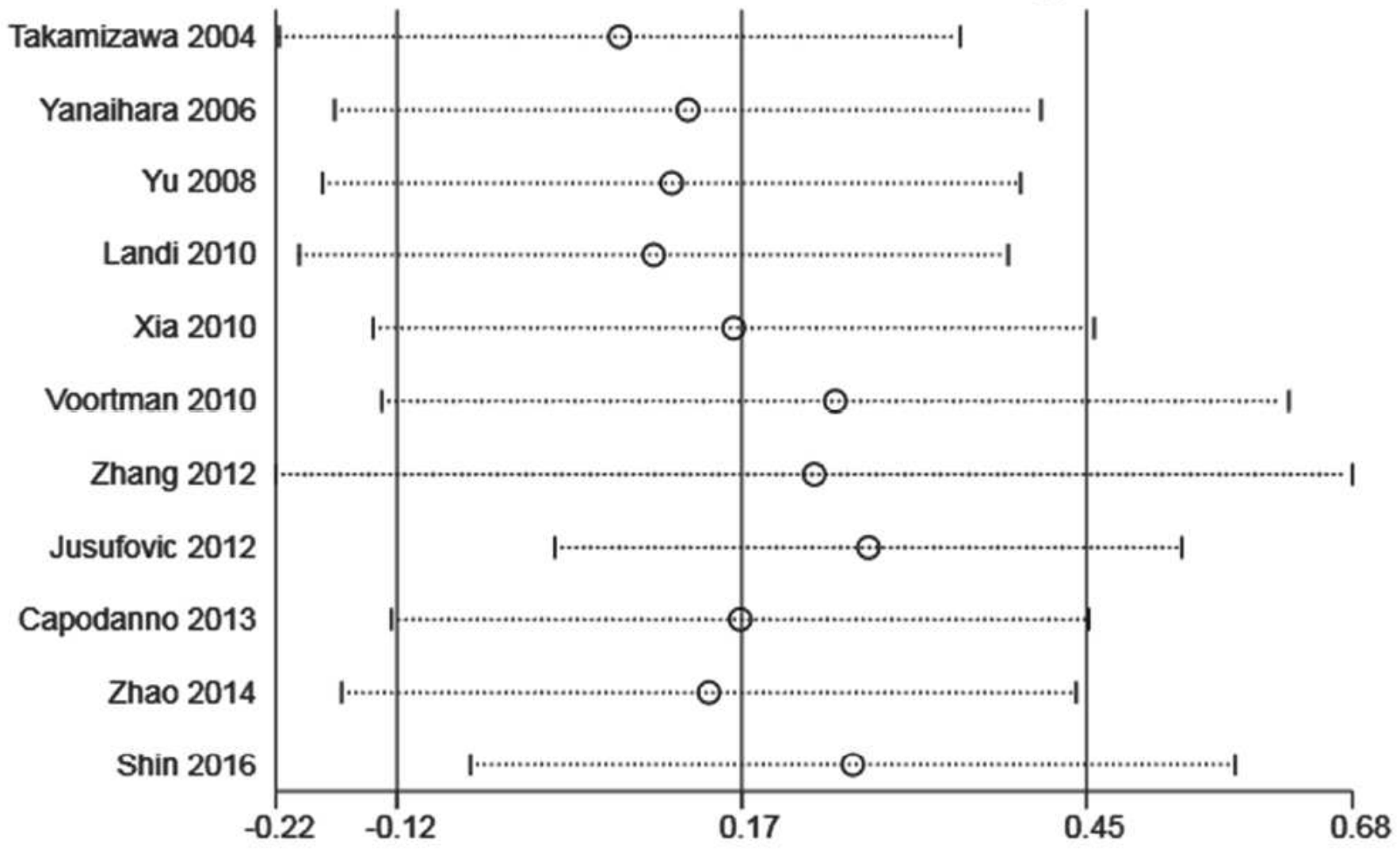

Figure 7

Sensitivity analysis to assess the stability of results. 